\title{
Vein of Galen aneurysmal malformation
}

INSERM

\section{Source}

INSERM. (1999). Orphanet: an online rare disease and orphan drug data base. Vein of Galen aneurysmal malformation. ORPHA:1053

Vein of Galen aneurysmal malformation (VGAM) is a congenital vascular malformation characterized by dilation of the embryonic precursor of the vein of Galen. It is a sporadic lesion that occurs during embryogenesis. 